\title{
Experiencia vital y tragedia en una familia de inmigrantes: Panorama desde el puente de Arthur Miller
}

\author{
Vital experience and tragedy in an immigrant \\ family: Arthur Miller's A View from the Bridge
}

Daniel G. Campos

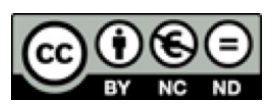

Esta obra está bajo una licencia Creative Commons Reconocimiento-No comercial-Sin Obra Derivada 
Artículos

\title{
Experiencia vital y tragedia en una familia de inmigrantes: Panorama desde el puente de Arthur Miller ${ }^{1}$
}

\author{
Vital experience and tragedy in an inmigrant \\ family: Arthurd Miller's A View from the Bridge
}

\author{
Daniel G. Campos ${ }^{2}$ \\ Brooklyn College - City University of New York \\ dcampos@brooklyn.cuny.edu
}

Recibido: 17 de enero de 2017 Aprobado: 27 de junio de 2017

\section{Resumen}

Este artículo presenta una lectura de Panorama desde el puente, de Arthur Miller, enfocada en las formas en que la obra retrata la vida personal y familiar del inmigrante. La lectura se desarrolla de lo particular a lo universal, es decir, de las experiencias de una familia italiana en el Brooklyn del siglo XX, como ejemplar de las vivencias de familias de inmigrantes en particular, a vivencias y conflictos que

1 Este artículo desarrolla temas presentados en el conversatorio "Panorama desde el puente: migración y relaciones humanas", que se realizó el miércoles 10 de agosto de 2016 en el Teatro de la Aduana bajo el marco de la Cátedra Sara Astica de la Escuela de Artes Dramáticas, Universidad de Costa Rica (UCR). El evento se organizó a propósito del montaje de la obra de Arthur Miller producido en conjunto por la Compañía Nacional de Teatro y el Teatro Universitario en 2016. Agradezco a Moy Arburola, entonces directora de la Compañía Nacional de Teatro y a Liliana Biamonte, Docente Coordinadora de la Cátedra Sara Astica, por la invitación a participar en el conversatorio. También agradezco a los otros miembros del panel, Javier Montenegro (actor del elenco), Alexánder Jiménez (filósofo y profesor de la UCR) y Tatiana de la Ossa (directora), por comentarios que enriquecieron la elaboración de mis ideas en este trabajo. A Tatiana le agradezco, además, el permiso para citar su excelente traducción al español centroamericano contemporáneo del texto en inglés de $A$ View from the Bridge.

2 Ph.D en Filosofía por Pennsylvania State University. Profesor Asociado, Departamento de Filosofía en Brooklyn College-City University of New York. 
atañen a la condición humana en general. La primera parte provee una descripción fenomenológica de la experiencia personal del inmigrante como experiencia de transformación a nivel (i) de sus afectos, (ii) de sus relaciones con lugares, personas y comunidades y (iii) de los fines que concibe y persigue para su vida. La segunda aborda la relación entre la ley, la justicia y las costumbres morales de una comunidad y como esta relación afecta la vida de los personajes. La tercera, a modo de conclusión, discute cómo esta relación contribuye a provocar una tragedia familiar que refleja la tragedia de muchos inmigrantes en el mundo actual. El análisis se apoya en la puesta en escena de la obra dirigida por Tatiana de la Ossa y coproducida por la Compañía Nacional de Teatro y el Teatro Universitario de Costa Rica en 2016.

Palabras clave: Arthur Miller; inmigración; ley; justicia; moral

\begin{abstract}
:
This article presents an interpretation of Arthur Miller's A View from the Bridge. It focuses on the ways the play portrays the personal and family experience of the immigrant. The interpretation proceeds from the particular to the universal-that is, from the experiences of an Italian family in twentieth-century Brooklyn, as an exemplar of the lives of immigrant families in particular, to experiences and conflicts that pertain to the human condition in general. The first part presents a phenomenological description of the personal experience of immigrants as an experience of transformation at the level of their (i) affects, (ii) relations to persons, places, and communities, and (iii) the ends that they conceive and pursue for their lives. The second part addresses the relation between law, justice, and the mores of a community, and how this relation affects the characters' lives. The third part, by way of conclusion, discusses how this relation contributes to cause a family tragedy that reflects the tragedy of many immigrants in the world today. The analysis draws from the 2016 production of the play by the Compañía Nacional de Teatro and the Teatro Universitario in Costa Rica, directed by Tatiana de la Ossa.
\end{abstract}

Keywords: Arthur Miller; immigration; law; justice; mores 


\section{Introducción}

Las experiencias de vida de los inmigrantes y sus descendientes tienen matices y tonos propios, aspectos particulares. Sin embargo, son también vivencias que revelan aspectos universales de la experiencia humana: amor, solidaridad, esperanza, soledad, vulnerabilidad, prejuicios, envidia, mezquindad, explotación, coraje, lamento, perdón y gracia. La presencia de asuntos universales de la experiencia humana en las vidas de unos pobres estibadores y sus familias en un barrio marginal de Brooklyn es uno de los temas centrales de la obra Panorama desde el puente de Arthur Miller ${ }^{3}$. La puesta en escena, dirigida por Tatiana de la Ossa y coproducida por la Compañía Nacional de Teatro (CNT) y el Teatro Universitario (TU) en Costa Rica en el 2016, mostró la profundidad artística de la obra de Miller, dramaturgo nacido en Brooklyn en 1915, y la relevancia actual de los asuntos abordados en ella.

En la obra, el abogado de clientes pobres y casos ordinarios Paulino Alfieri nos presenta la historia trágica de su antiguo cliente Edi Carbone, un estibador brooklyniano de origen italiano en el barrio de Red Hook en los años cincuenta del siglo XX. Al narrarla, Alfieri imagina que esa historia, como otras similares, bien podría haber sido escuchada por otros abogados en lugares y épocas muy distintos:

cuando las partes me explican cuál es el problema ... se me viene la idea de algún momento en los tiempos del César, en Calabria talvez, o en el acantilado de Siracusa, en donde otro abogado, vestido de forma completamente diferente a la mía, oyó la misma queja y se sentó así, tan impotente como estoy yo ahora... y miró correr su inexorable cauce sangriento (Miller, 2016, pp. 4-5).

En este ensayo esbozaré algunas particularidades, mostradas en la obra de Miller, de la experiencia de los inmigrantes y sus descendientes en el Brooklyn del siglo $\mathrm{XX}^{4}$. Estas particularidades, a su vez, nos llevarán a vislumbrar algunos aspectos universales de esa experiencia de vida, especialmente en cuanto a la relación entre la ley, la justicia y las costumbres morales de una comunidad. Este esbozo es apenas uno entre muchos posibles. No se analizará, por ejemplo, el papel del machismo, el patriarcado y la opresión de la mujer en el desarrollo de la

3 Este artículo extrae las citas del texto traducido por Tatiana de la Ossa en Miller (2016). Una versión del texto original en inglés se encuentra en Miller (2015).

4 No se presentará una contextualización histórica detallada. Sin embargo, un texto clásico para comprender la experiencia de inmigrantes italianos, alemanes, judíos, irlandeses y chinos, entre otros, en Nueva York a finales del siglo XIX y principios del siglo XX es Riis, 2010. Otros textos de interés incluyen Hesse-Biber, 1979, sobre inmigrantes italianos en el siglo XIX y principios del XX, Anbinder, 2002, sobre inmigrantes irlandeses en el siglo XIX, y McKeown, 2003, sobre inmigrantes chinos en el siglo XX. En todos los casos, se trata de inmigración hacia los Estados Unidos de América. 
tragedia en el seno de la familia Carbone. Pero se espera que este abordaje ilumine aspectos importantes de la vivencia del inmigrante como experiencia humana.

Este tema es de gran relevancia contemporánea debido a los masivos flujos migratorios a nivel mundial. En el 2016, la sociedad costarricense enfrentó crisis de migrantes cubanos, haitianos y africanos que pretendían llegar por ruta terrestre hasta los Estados Unidos de América (EE.UU.). Costa Rica es, además, un país que recibe inmigrantes de Centro y Suramérica, entre otras regiones. Resultó evidente la importancia actual de meditar sobre la vivencia de los migrantes e inmigrantes para responder de forma ética y justa a sus problemas. Además, en EE.UU. el discurso xenofóbico y anti-inmigrante de un político contribuyó a que fuera electo presidente de ese país en noviembre de 2016. La puesta en escena de Panorama desde el puente por parte de la CNT y el TU y dirigida por De la Ossa, por tanto, resultó sumamente oportuna. La presente lectura del texto de Miller se apoya implícita y explícitamente en esa puesta en escena para abordar el tema de la experiencia vital de los inmigrantes. Por esto, cada vez que se introduzca un personaje se nombrará al actor o actriz que lo ha interpretado. Se asumirá también que la presente lectura del texto conlleva el filtro o enfoque sugerido por varios aspectos de la puesta en escena, tales como la interpretación de los actores y la escenografía, según mi apreciación. Cabe enfatizar de nuevo, sin embargo, que el propósito central del artículo es proveer una vía, entre muchas posibles, para entender la experiencia vital de personas inmigrantes como experiencia humana a partir de la obra de Miller y la referida puesta en escena.

\section{La experiencia personal del inmigrante: afectos, relaciones y fines}

La experiencia personal del inmigrante puede ser considerada como una vivencia en tres niveles que se relacionan entre sí. El inmigrante vive una experiencia de cambio y transformación a nivel (i) de sus afectos, (ii) de sus relaciones con lugares, personas y comunidades y (iii) de los fines que concibe y persigue para su vida (Campos, 2011). Esta experiencia triádica se ve reflejada en las vivencias de los personajes de Panorama desde el puente.

Al referirme a la experiencia personal como triádica -como coordinación de tres aspectos: afectos, relaciones y fines- hago alusión al pensamiento del filósofo estadounidense Charles S. Peirce. Según Peirce, nuestra personalidad es la coordinación de estos tres aspectos de nuestra experiencia en un proceso mental-corporal continuo y evolutivo (Peirce, 1992). Este proceso se caracteriza por su finalidad, es decir, guiado por un telos, un fin general que sin embargo no es fijo y dado de antemano, como el telos aristotélico, sino que puede evolucionar e incluso ser transformado por nuestras decisiones y acciones. Se caracteriza también por su relación con los procesos evolutivos de otras personas y de nuestros medios biológicos, sociales, políticos, económicos y culturales. Se caracteriza, además, por su espontaneidad y 
afectividad. La espontaneidad es el grado de libertad que todo proceso personal preserva para evolucionar, para transformarse. Las personas conservan la posibilidad de mudar de hábitos, de las creencias y disposiciones que tienden a guiar sus decisiones y acciones. La afectividad, por otra parte, es la forma en que sentimos cualitativamente nuestros procesos personales en relación con otras personas y con nuestro entorno. La afectividad puede a su vez caracterizarse por tres niveles: las sensaciones (feelings), las emociones (emotions) y los sentimientos (sentiments), como se ilustrará más adelante.

El anterior es, por supuesto, un modelo peirceano muy general de la experiencia personal. En este ensayo no se abordará la sustentación teórica de esta forma de entender la experiencia personal ${ }^{5}$. Tampoco se presume que sea el único modelo filosófico posible para entenderla e iluminarla. Se propone, sin embargo, aplicarlo para entender la experiencia de personas inmigrantes ya que es un modelo esclarecedor, sin ser único ni exhaustivo. Un abordaje general peirceano de la experiencia de personas inmigrantes se ha propuesto en Campos, 2011, y se ha desarrollado con mayor amplitud y profundidad en Campos, 2017. En este artículo se aplicará específicamente para describir la experiencia de personas inmigrantes según la obra de Miller.

Al inicio de la trama, encontramos a la familia Carbone -Edi (Antonio Rojas), su esposa Beatriz (Ana Clara Carranza) y su sobrina Catarina o Kati (Natalia Arias)- preparándose para hospedar y acoger a Marco (Erick Córdoba) y Rodolfo (Javier Montenegro), primos sicilianos de Bea que desembarcan ilegalmente en Brooklyn ayudados por traficantes de personas. En el transcurso de aproximadamente seis meses de convivencia se desarrollarán los hechos que desenlazan en tragedia para todos los personajes. En este contexto, la experiencia de Marco y Rodolfo como inmigrantes puede ser considerada desde los tres niveles mencionados.

Primero, a nivel afectivo los sicilianos recién llegados a Brooklyn experimentan sensaciones, emociones y sentimientos característicos de las vivencias del inmigrante. Las nuevas sensaciones corporales, como escuchar el sonido de nuevas lenguas, ver paisajes marinos y urbanos distintos, sentir nuevos olores y sabores, y la humedad y temperatura distintas en la piel, forman parte sutil y, a menudo, ignorada parte de esas vivencias. En el texto original de Miller, estas sensaciones son apenas sugeridas, por ejemplo, por el olor a café que impregna al barrio portuario debido a la descarga de un buque cargado de costales repletos del grano, por la sonoridad del italiano entremezclado con el inglés de Marco y Rodolfo o por la del inglés brooklyniano de los estibadores. En la puesta en escena dirigida por De la Ossa, sin embargo, toda esa gama de sensaciones ganó vivacidad pues el montaje muestra la vida del barrio de Red

5 Aunque lo he hecho con cierto detalle, sin embargo, en Campos (2011) el modelo interpretativo de la afectividad según Peirce se explica con mayor profundidad y se basa en una elaborada sustentación teórica en Trout (2010). 
Hook, con sus tiendas de abarrotes, fruterías, pescaderías, apartamentos pequeños de cocinas ajetreadas, tendederos de ropa mojada secándose al aire libre y demás.

Los hermanos inmigrantes pasan además por situaciones sorpresivas, problemáticas o inesperadas que provocan intensas emociones, esto es, reacciones corporales y afectivas en respuesta a sus situaciones concretas. Marco y Rodolfo expresan alegría al conocer el apartamento de los Carbone o el jornal semanal en dólares de un estibador. Rodolfo se deslumbra con la vitalidad urbana de Nueva York y con júbilo canta, baila y se apasiona por Catarina. Una de las cuestiones de la trama es si esa pasión amorosa, de atracción y erotismo juvenil, que parece sincera, llega a tener la profundidad del sentimiento de amor cuidadoso y comprometido, o si es una emoción pasajera. Edi va más allá y cuestiona no solo la profundidad sino la propia sinceridad de la emoción amorosa: en repetidas ocasiones le expresa a Catarina, a Beatriz y al mismo Alfieri (Luis Fernando Gómez) su certidumbre de que Rodolfo quiere casarse con Catarina únicamente para hacerse ciudadano estadounidense y obtener las garantías legales y laborales que esto conllevaría. Cuando Kati parece acoger esta sospecha y cuestiona a Rodolfo, este manifiesta indignación: "quiero que seás mi esposa y quiero ser un ciudadano. Decile eso [a Edi], o se lo digo yo ... Y también decile, y te lo decís a vos también, que yo no soy un pordiosero, y que vos no sos un caballo, ni un regalo, ni un favor para un inmigrante pobre" (Miller, 2016, p. 51). La indignación expresada con fuerza en la actuación de Montenegro lo lleva a la ira en uno de los pasajes importantes de la obra:

Estoy furioso. ¿Creés que estoy tan desesperado? Mi hermano está desesperado, no yo. ¿Pensás que voy a cargar el resto de mi vida con una esposa a la que no amo sólo para ser americano? ¿Es tan maravilloso? ... [En Italia] lo que no tenemos es trabajo. Quiero ser ciudadano americano para poder trabajar... esa es la única maravilla aquí... ¡trabajo! ¿Cómo podés ofenderme de esa manera Catarina? (Miller, 2016, p. 51).

Rodolfo se refiere así a la situación de Marco, su hermano mayor, quien ha dejado a su esposa y tres hijos en Sicilia con el propósito de trabajar en los muelles de Brooklyn y enviarles dinero. En la escena temprana en que los hermanos llegan a casa de los Carbone y conocen a su prima Beatriz, Marco ya ha dicho: “qué puedo hacer? El mayor está enfermo del pecho. Mi esposa... le da de comer hasta de su propia boca. La verdad, si me quedaba allá no los iba a ver crecer. Se comen hasta la luz del Sol" (Miller, 2016, p. 20). La desesperación del inmigrante económico ante la situación en su lugar de origen es una de las emociones más fuertes que plasma la obra.

Y esta desesperación viene acompañada de otra emoción intensa: el miedo debido a su situación vulnerable de ilegalidad y a la hostilidad del entorno social y político que los rodea. Rodolfo se lo expresa a Kati: "una vez sea ciudadano podría trabajar en cualquier parte y encontraría mejores trabajos y tendríamos una casa, Catarina. ¡Si no estuviera con el miedo este que 
me arresten, ya hubiera empezado a hacer algo formidable!" (Miller, 2016, p. 50). El montaje dirigido por De la Ossa muestra claramente este miedo constante que sienten los trabajadores ilegales o "submarinos" en el barrio portuario: la policía los asedia, los persigue ante la menor sospecha y, de ser atrapados, serían deportados sin contemplaciones de acuerdo con la ley migratoria vigente. Pero el miedo no es solamente a la policía, riesgo identificable, sino a los informantes de esta. Cualquier persona del barrio o del puerto, como bien lo advierte Edi, puede ser un enemigo al acecho. Irónicamente, el propio Edi utiliza esta amenaza para controlar los movimientos de Rodolfo y sus salidas nocturnas con Kati. Incluso los estibadores italo-estadounidenses rivalizan con los inmigrantes ilegales, pues estos, mientras deben dinero a la red de tráfico de personas, socia mafiosa del sindicato, tienen el trabajo asegurado. Miguel, un estibador amigo de Edi, al saber que Rodolfo y Marco tienen trabajo todos los días, ironiza: "eso es lo que tenemos que hacer: irnos de este país y regresar bajo el agua, entonces...jtendremos trabajo!" (Miller, 2016, p. 29).

La puesta en escena muestra en repetidas ocasiones a los estibadores nativos hostilizando física o verbalmente a los estibadores foráneos, sin llegar a romper el código comunitario de silencio ante la policía. No los denuncian, pero les recuerdan su vulnerabilidad, sobre todo a Rodolfo. Como este ha enamorado a Kati, quien antes coqueteaba con Luis, este muchacho del barrio, por lo cual sus amigos asedian a Rodolfo por las calles de Red Hook, burlándose de él o amedrentándolo físicamente. Rodolfo vive bajo constante asedio e incluso Marco teme por él. Eventualmente Edi se convertirá en la principal amenaza para la seguridad y el bienestar de ambos. En resumen, alegría, júbilo, pasión amorosa, indignación, ira, desesperación y miedo son algunas de las emociones que forman parte de la experiencia afectiva de los hermanos sicilianos. Ellos, además, experimentan sentimientos característicos de la vivencia del inmigrante. Por sentimientos quiero decir disposiciones afectivas que se asientan más profundamente en la persona y la guían en sus comportamientos habituales, en general, no solamente en sus respuestas a situaciones concretas y temporales, como las emociones. El sentimiento preponderante al principio es la esperanza. Al llegar a Brooklyn, Marco espera quedarse "cuatro, cinco o seis años" (Miller, 2016, p. 20) para ganar dinero y sustentar a su mujer y tres hijos, antes de regresar. Las esperanzas de Rodolfo, más joven y soltero, son más cercanas al desaforado american dream o sueño estadounidense. Sus ilusas esperanzas son incluso contradictorias, pues dice querer quedarse para siempre en EE.UU. pero de inmediato se contradice: "quiero ser un americano. Y luego quiero regresar a Italia cuando sea rico, y voy a comprar una motocicleta" (Miller, 2016, p. 22). Marco pronto observa: "cuando no tenés esposa tenés sueños" (Miller, 2016, p. 22). Sus respectivas esperanzas son sentimientos en el sentido de guiar sus actos: Marco trabaja durísimo y ahorra todo el dinero que puede para enviarlo a su familia en Sicilia; Rodolfo se lanza a explorar la vida neoyorquina, con sus cines, su moda, su música y su chica Kati, sin preocuparse por ahorrarlo todo. 
Por esto, Marco siente una soledad que no afecta a Rodolfo. Después de algún tiempo trabajando en los muelles, Marco le confirma a Bea estar más tranquilo pues ha podido enviar dinero a Sicilia y su mujer ha comprado medicina para su hijo mayor. Sin embargo acota: "pero me siento solo" (Miller, 2016, p. 43). Es una soledad amenizada por la esperanza: "en nuestro pueblo hay muchas familias que tienen niños que no conocen a sus padres. Pero yo iré a casa. Calculo que en tres o cuatro años" (Miller, 2016, p. 43). Pero es soledad al fin. Y este sentimiento, sugerido por el texto de Miller, se ha visto claramente plasmado en el montaje referido. Cuando no está trabajando en los muelles, a Marco lo observamos en casa de los Carbone, generalmente silencioso, escribiendo cartas o leyendo una y otra vez las que ha recibido, cenando modestamente y un tanto preocupado por la extravagancia de Rodolfo, quien sí busca la vida callejera y nocturna. Es la sacrificada soledad de quien tiene sus principales vínculos afectivos lejos, allá en casa, atravesando el inmenso océano.

Esta vivencia sentimental de hecho está íntimamente ligada al segundo nivel de la experiencia personal del inmigrante: las relaciones con lugares, personas y comunidades. Ambos hermanos han dejado atrás su pueblo natal, el lugar donde crecieron, jugaron, trabajaron, establecieron afectos y cultivaron vínculos familiares y sociales. Dejar atrás la relación orgánica, corporal y espacial con el lugar de origen es difícil. En los alrededores de su pueblo había playa, mar, vergeles con naranjos y limones. La fuente en la plaza era el principal punto de referencia y de convergencia social. Rodolfo le expresa a Kati que no puede creer que en Nueva York no haya fuentes (Miller, 2016, pp. 30-31). Es un detalle importante de su vivencia porque muestra que debe aprender a reorientarse y navegar el entorno, en este caso urbano y neoyorquino. Hay muelle, barrios densamente poblados, avenidas comerciales, cines, teatros. Pero no hay fuentes. ¿Dónde se encuentran las personas a conversar?

La escenografía del montaje, a cargo de Ronald Villar-Chumi, es importante para visualizar este nivel de experiencia. En el centro del escenario se observa, sobre una plataforma de madera, el apartamento de los Carbone con sus varios ambientes: la sala, el comedor, la cocina, los dormitorios, es decir, los espacios de convivencia íntima. Alrededor del apartamento, se observa la vida del barrio con sus tiendas y edificios de apartamentos densamente poblados. Estos recuerdan a los tenements (casas convertidas en decenas de diminutos apartamentos) de fines del siglo XIX y principios del XX en Nueva York donde se aglomeraban miles de inmigrantes europeos (Riis, 2010). Hay espacios exclusivamente masculinos, como las aceras y callejones donde los estibadores juegan al azar o el gimnasio de boxeo donde pelean. En los linderos del barrio, incluso por detrás de las zonas de butacas, el escenario muestra el puerto de Red Hook con sus grúas, plataformas y maquinaria. La puesta en escena muestra entonces que a Rodolfo los muelleros no lo quieren ver en las calles ni en el gimnasio de boxeo. Marco, por su parte, extraña a su familia, a su mujer y sus hijos. Añora estar con ellos, compartir la cotidianeidad de 
la vida familiar. Estas relaciones personales se mantienen vivas en su corazón pero no disfruta de la presencia orgánica, corporal: no acaricia a su esposa e hijos, no los ve crecer, no los oye jugar o cantar o llorar, no le hace el amor a ella. Las relaciones personales atan a Marco con su lugar de origen de una forma que no atan a Rodolfo. Este establece más libremente vínculos con personas en el lugar de llegada, principalmente con Kati. Por ello se les ve más en la calle, yendo y viniendo de sus aventuras neoyorquinas, aunque esto signifique un riesgo para Rodolfo. Mientras tanto a Marco se le observa más en casa, como ya se ha mencionado.

En cuanto a las comunidades de origen y llegada, la relación es compleja. En Sicilia ambos pertenecen a la comunidad de forma espontánea y fluida, sin hacer esfuerzos por merecerlo. Pero en Brooklyn no es así. En los muelles, a Marco se le admira como fortísimo estibador pero se le resiente su condición de submarino, mientras que a Rodolfo se le rechaza por no apegarse a las costumbres y comportamientos de los "machos" estibadores. Sufre burlas y hostigamiento constantes. Se les acepta a ambos como italianos, pero se les hace sentir que no son italo-estadounidenses cuando se rivaliza por trabajo o mujeres. Estos son apenas algunos detalles de la obra y puesta en escena que muestran la importancia de las relaciones geográficas, personales y comunitarias en la vivencia personal del inmigrante.

Considerando de nuevo la experiencia afectiva, los hermanos sí comparten un sentimiento de desconfianza y vulnerabilidad, aunque Marco se muestras más consciente de los riesgos que corren y, en parte por ello, actúa con más cautela. El entorno social y político es hostil. Como ya se ha mencionado, la ley castiga rigurosamente la inmigración ilegal y la policía acecha, mientras la propia comunidad italo-estadounidense se encarga de mostrarles lo que deben y lo que no deben hacer. En la puesta en escena lo observamos: pueden trabajar, pero se resiente que trabajen los "submarinos" cuando hay lugareños desempleados; pueden jugar al azar o boxear, pero no deben, como Rodolfo, enamorar a las muchachas locales, propiedad de los estibadores nativos. Incluso el entorno familiar es complejo y adverso. Edi, el patriarca, no acepta que Rodolfo corteje a Kati, su sobrina, y considera el noviazgo de estos un robo desautorizado e irrespetuoso. Poco a poco las pasiones lo llevan a convertirse en la principal amenaza para los hermanos. Estos, ante el riego creciente, sienten desconfianza. Marco actúa con cautela, ordenando a Rodolfo ser respetuoso del silencio en la casa, no salir tarde con Kati, no buscar la calle, no provocar a Edi. Rodolfo, por su parte, responde con rebeldía y un astuto desafío al ahorrar trescientos dólares y proponer matrimonio a Kati.

Esto nos lleva a considerar el tercer nivel de la experiencia personal del inmigrante: los fines que concibe y persigue para su vida. Marco concibe sus propósitos de manera típica del inmigrante por causas económicas que deja en casa a su familia. Él quiere trabajar, ahorrar el máximo de dinero posible, enviarlo a su mujer para sustentar a su familia y regresar a casa en 
cuanto sea posible con ahorros y recursos económicos para no emigrar más. Por ello, no busca establecer vínculos personales o comunitarios permanentes en Red Hook, ni sueña con salir del barrio portuario para vivir y trabajar en Manhattan. En parte por ello su experiencia afectiva consiste principalmente en emociones como la desesperación, indignación y sentimientos que pasan de la esperanza a la soledad y desconfianza. Quizá podríamos decir, para enfatizar sus fines, que Marco es más un migrante que planea retornar a casa que un inmigrante que quiere hacer su nuevo hogar en una nueva tierra.

Su hermano menor, sin embargo, persigue otros fines. Rodolfo sí es un inmigrante. Quiere ganarse la vida trabajando dignamente. Al llegar le anuncia a Edi: "trabajaremos duro, todo el día, toda la noche" (Miller, 2016, p. 21). Se entiende que salda sus deudas con los traficantes de personas y el sindicato, pues de otra forma pagaría las consecuencias. Y de hecho, más avanzada la trama, descubrimos que ha ahorrado dinero para casarse con Kati. Pero he aquí fines que no se ajustan a lo esperado para un inmigrante ilegal por causas económicas. Rodolfo quiere cultivar su vida afectiva, personal y social en Nueva York, no solamente sobrevivir un período laboral temporal hasta suplir necesidades familiares en Sicilia. Desea enamorar a Kati, divertirse, ir al cine, comprar discos y bailar con ella. Gusta también de comprar ropa y zapatos para vestir a la moda. Quiere ir a Manhattan y explorar Times Square y los teatros de Broadway. Desea tener una vida afectiva plena y cultivar vínculos personales y sociales con el lugar de llegada. Sicilia ha quedado atrás. Sus ilusiones de regresar rico a Sicilia son ensoñaciones pasajeras. Para enfatizar el contraste con Marco, Rodolfo no es tanto un migrante con aspiraciones de retorno a Sicilia como un inmigrante con aspiraciones de construir una nueva vida en Nueva York y disfrutarla para sí y con Kati.

Los fines de Rodolfo, sin embargo, al no ajustarse a lo esperado de un "submarino" de origen italiano llegado a un barrio portuario brooklyniano, lo llevan a enfrentar conflictos y obstáculos que Marco no enfrenta para sí mismo. Esto nos lleva a analizar uno de los conflictos centrales de la obra: aquel entre los fines que las personas inmigrantes y sus descendientes conciben, quieren y persiguen para sus vidas, y las normas éticas, legales y sociales que delimitan lo que es posible y aceptable para ellos.

\section{Ley, justicia y costumbres morales en la vida de las familias de inmigrantes}

Rodolfo, joven inmigrante italiano, proyecta fines personales que no se ajustan a las normas legales y morales que rigen las vidas de personas como él. Es decir, los fines de Rodolfo no se compaginan con los preestablecidos legal y socialmente para los inmigrantes. De allí surge 
un conflicto central de la obra. Por su parte Kati, como joven mujer descendiente de inmigrantes italianos, también concibe fines personales que no se ajustan a las normas que la sociedad y su entorno comunitario y familiar establecen para ella. Esto agrava el mencionado conflicto entre fines personales y normas vigentes que abordan el texto y el montaje de Panorama.

Para efectos de este análisis, distinguiremos entre tres tipos de normas que rigen la vida y las acciones de los personajes, a saber: la justicia, la ley y las costumbres morales. El sentido de la justicia se entenderá como un asunto ético, es decir, como aquello que lo personajes entienden por el bien y el mal y sus conceptos sobre cómo pueden realizar el bien. Como se propondrá más adelante, en la obra este sentido de justicia tiene matices similares al concepto de Henry David Thoreau de que todo ser humano tiene la capacidad de ser consciente de la justicia, percibir la injusticia y sentir que puede actuar para remediarla (1992). Por ley se entenderá un pacto social legislado y reglamentado que regula de lo que les es permitido o prohibido hacer a los personajes. Y por costumbres morales se entenderán los códigos de conducta aceptados por una comunidad e impuestos a sus miembros, independientemente de cualquier esfuerzo de justificación razonable de esos códigos. La compleja interacción entre el sentido de justicia, la legalidad y la moralidad comunitaria delimita y conduce las acciones de los personajes. Su influencia conjunta, aunada a las pasiones de cada uno, es tan fuerte que parece determinarlas como un destino implacable y trágico.

En su discurso inicial, el abogado Alfieri presenta el contraste entre justicia y ley por el cual los estibadores, descendientes de sicilianos, tienden a desconfiar y mantenerse distantes de él: "un abogado representa a la ley y, en Sicilia, de donde vinieron sus padres, la ley no representa nada amigable desde que fueron vencidos los griegos" (Miller, 2016, p. 3). La escenografía muestra esta distancia al colocarse el despacho de Alfieri en una plataforma elevada, oscura y completamente aislada del resto del barrio de Red Hook. Aún más, continúa el abogado, en las calles de Red Hook y del Nueva York italiano "muchas personas fueron justamente asesinadas por hombres injustos" (Miller, 2016, p. 4) en las disputas de la mafia. La justicia se puede hacer por medios que no son legales. Por ello, "la justicia aquí es un asunto muy importante" (Miller, 2016, p. 4). Y sin embargo, al ubicarse Red Hook en Brooklyn y no en Sicilia, algunas cosas han cambiado: "esta es la garganta de Nueva York por donde se engullen las toneladas del mundo. Y hoy somos más civilizados, totalmente americanos. Ahora pactamos con acuerdos parciales" (Miller, 2016, p. 4). Es decir, los estadounidenses descendientes de italianos y los inmigrantes asimilados a la cultura dominante están dispuestos a negociar su sentido de la justicia y concertar acuerdos prácticos, por ejemplo, para evitar tragedias como las resultantes de los ajusticiamientos por fuera de la ley. La ley, aunque no siempre sea justa, es civilizadora. 
El discurso contextualiza un problema clásico: ¿qué debemos hacer cuando nuestro sentido de la justicia y la letra de la ley entran en conflicto? Una obra de teatro clásico que aborda esta cuestión es Antígona de Sófocles (2009). Creonte, tío de Antígona y nuevo rey de Tebas, ordena que no se le dé sepultura a Polinices, hermano de Antígona, por motivo de traición en su guerra fratricida contra Etéocles, el otro hermano. Sin embargo, dejar insepulto el cuerpo de Polinices violentaría la justicia divina. Antígona entonces se rebela contra la orden legal de Creonte y sepulta a Polinices sin amedrentarse por las consecuencias. Su compromiso con la justicia divina es más fuerte que con la ley de Tebas. Dado el conocimiento de Arthur Miller sobre la historia de la tragedia, es razonable especular que Antígona puede haber influenciado Panorama. Según el crítico M. W. Steinberg, Panorama es la tragedia más clásica de Miller (1960). Por un lado, el narrador Alfieri funge como coro para enfatizar la significancia generalizada de los acontecimientos. Por otro, Panorama enfatiza, más que otros dramas anteriores de Miller, el carácter del protagonista, Edi, como un hombre que se ve empujado hacia su propia destrucción por fuerzas mayores que la suya (1960, p. 339) ${ }^{6}$. Además el propio Miller, según lo cita Steinberg, escribió que el personaje Edi Carbone es capaz de llegar al punto del sacrificio para defender su propio concepto, aunque fuera engañoso, del bien (right), la dignidad y la justicia (1960, p. 338) ${ }^{7}$. Este personaje que se sacrifica por su concepto de la justicia puede asociarse razonablemente a Antígona, aunque el concepto de Edi sea confuso mientras que el de Antígona sea claro.

El personaje de Antígona, por su parte, influyó en el pensamiento del escritor estadounidense Henry David Thoreau en cuanto a la desobediencia civil. En su ensayo "Resistance to Civil Government", Thoreau plantea que hay leyes injustas (1992, p. 233). Pero no podemos invertir toda nuestra energía reformando o resistiendo todas las leyes injustas porque nuestras vidas tienen múltiples propósitos, sentidos e intereses (1992, p. 231-232). Entonces Thoreau pregunta cuándo debemos desobedecer. Su respuesta, su principio de desobediencia civil, es que debemos desobedecer la ley cuando nos obliga a ser agentes directos de la injusticia en contra de otra persona. Es decir, debemos desobedecer la ley cuando nos obliga a actuar injustamente hacia otras personas (1992, p. 233).

Quizá este principio de resistencia civil en nombre de la justicia guíe instintivamente a la comunidad italo-brooklyniana a recibir y acoger a los inmigrantes ilegales provenientes de Sicilia, aunque la ley de inmigración vigente y las prácticas policiales incentiven a denunciarlos.

6 Steinberg aclara que este énfasis es apenas relativo, pues en Panorama como en la tradición de la tragedia cristiana, el personaje tiene un cierto grado de libertad y responsabilidad ya que los acontecimientos podrían haber sido diferentes.

7 Steinberg cita un artículo escrito por Miller en el New York Times el 25 de setiembre de 1955. 
Aunque los residentes de origen italiano de Red Hook no articulen explícitamente el principio de resistencia civil, sienten que sería injusto acatar la ley y denunciar a las autoridades de migración a personas que solo buscan trabajar para sobrevivir. En el montaje se observa a sindicalistas repartiendo un panfleto a los estibadores que es decomisado por la policía. Luego, personajes como Luis el estibador y Antonia, muchacha trabajadora del barrio, interactúan con el público repartiendo el mismo panfleto. En este se lee:

Sindicato Muelle 41. Comunicado urgente. Nuevas reformas a la Ley de Inmigración y Nacionalidad de 1952 (McCarran-Walter Act) afectan a la comunidad migrante. El gobierno de los Estados Unidos de América está haciendo a los migrantes caer en un estatus de ilegalidad al considerar a todo extranjero un potencial quebrantador de la ley. América se está aislando, cerrando sus puertas con esta nueva ley ... Ahora solamente podrán aplicar a la nacionalidad estadounidense los hombre mayores de 18 años, que demuestren haber entrado legalmente al país, haber vivido de 3 a 5 años, 'apegado a los principios de la Constitución; un extranjero no tiene buen estatus moral si es borracho, ha cometido adulterio, tiene más de una esposa, vive de las apuestas, ha mentido a las autoridades de Inmigración o ha estado en prisión por más de 180 días, por cualquier razón, o ha sido declarado culpable de cualquier delito ${ }^{8}$.

En esta interpretación de la obra, entonces, los sindicalistas, estibadores y vecinos del barrio practican desobediencia civil. Acogen a los submarinos, aunque esto conlleve riesgo. Antes de la llegada de Marco y Rodolfo, por ejemplo, Edi le advierte a Bea y Kati que no deben decir nada a nadie respecto a la presencia de los inmigrantes en su casa, pues en cualquier lugar puede haber soplones y traidores: "aquí se la están jugando con el gobierno de los Estados Unidos, con la Oficina de Inmigración. Si lo dicen, es porque lo saben, si no lo dicen es porque no lo saben" (Miller, 2016, p. 14). Es decir, si ellas cuentan a alguien que están hospedando a los submarinos, se colocan en riesgo ante el gobierno y sus leyes. Deben estar del lado de la justicia, de acoger a los necesitados aún en condición de ilegalidad, pero evitando el conflicto legal directo.

En la obra de Miller, sin embargo, la relación clásica entre justicia y ley se complica en la práctica, en la vivencia familiar y social, por la influencia de los códigos morales aceptados por la comunidad e incorporados como sentimientos morales y pasiones por los personajes. Edi Carbone encarna los principales conflictos en este respecto. Aunque inicialmente advierte a Bea y Kati sobre los informantes, condenándolos, poco a poco se convierte en la peor amenaza para Rodolfo. Cuando Rodolfo ha empezado a desplegar su exuberancia juvenil y galantería, convirtiendo la sala del apartamento de los Carbone en un escenario de canto y baile para lucirse ante Kati, Edi le advierte: “mirá jovencito, ¿no querés que te arresten, ah?” (Miller, 2016, p. 24). Le manda guardar silencio, supuestamente para no alertar soplones. Gradualmente descubrimos, sin embargo, que la incomodidad de Edi tiene otras causas.

8 Reproducción fiel del panfleto repartido al público general durante la función. 
Por un lado, lo que incomoda a Edi sobre Rodolfo no es la ilegalidad, sino la ruptura de normas sociales, incluidas las de género. Rodolfo, como hemos visto, no se comporta como debería un trabajador ilegal, ahorrando todo su dinero y escondiéndose en casa. Según Edi, se comporta como un oportunista en busca de un pasaporte estadounidense. Pero, además Rodolfo no se comporta de acuerdo con los códigos de masculinidad de la sociedad patriarcal de la que desciende Edi, tales como el absoluto rechazo a realizar labores domésticas, el hermetismo emocional y la rudeza física. Edi se incomoda al descubrir que Rodolfo canta, baila, hace vestidos y cocina. Además, se siente avergonzado, pues ante la comunidad el muchacho forma parte de su familia y en los muelles, los estibadores empiezan a burlarse de Rodolfo, llamándolo por nombres derogatorios que sugieren homosexualidad, como "muñeco de papel" y "canario" (Miller, 2016, p. 26).

Edi se lo confiesa al abogado Alfieri la primera vez que lo visita para pedirle consejo legal con respecto a Rodolfo. Edi dice estar seguro de que Rodolfo solamente quiere enamorar a Kati y casarse con ella para obtener su residencia legal, ya que es un oportunista despilfarrador de su salario. Pero Alfieri le hace ver de varias formas que no hay ningún asunto legal en ello: "no hay nada ilegal en que una joven se enamore de un inmigrante", además solo "puedo tratar lo que es comprobable. ¿Lo entendés verdad? ¿Podés probarlo?”, y finalmente “aún cuando podás probar eso, no es cuestión que ataña a la ley" (Miller, 2016, p. 36). Edi, sin embargo, tiene dificultad para entenderlo y confunde la ley con las normas sociales que reducen al inmigrante ilegal a un trabajador furtivo cuando insiste: "estoy hablando de la ley" (Miller, 2016, p. 37). Frustrado, insinúa la homosexualidad de Rodolfo pues canta, baila y es un rubio platinado, posiblemente teñido: "el tipo no está bien, señor Alfieri" (Miller, 2016, p. 37). En el texto original en inglés se lee: "the guy ain't right" (Miller, 2015, p. 469). Ello enfatiza la confusión de Edi: como el tipo no está right o derecho, la ley debe decir algo al respecto para prohibirle embaucar a Kati en matrimonio. Ante las repetidas negativas de Alfieri, Edi exclama indignado: “¿quiere decirme que no hay ninguna ley para hombres que no están bien y que vayan y trabajen y se casen con una niña y...?" (Miller, 2016, p. 38). Pero no la hay, aunque Edi no pueda aceptar que la ley positiva, escrita, no contemple faltas a las normas morales sociales que él acepta. Su conflicto se complica aún más cuando Alfieri observa: "aquí solo queda una cuestión de tipo legal ... La manera en que entraron al país. ¿Pero no creo que vos querrás hacer algo al respecto, cierto?” (Miller, 2016, pp. 38-39). Aunque Rodolfo y Marco entraron ilegalmente al país, Edi parece ser sincero al exclamar: "ay, Jesús, no, yo no haría nada de eso, imagínese..." (Miller, 2016, p. 39). Para Edi no sería justo ni socialmente aceptable denunciar a los "submarinos". Su sentido de la justicia y las normas morales de su comunidad no lo permiten.

Sin embargo Alfieri percibe que el corazón de Edi alberga una pasión que lo llevará a violentar tanto su sentido de la justicia como los códigos morales de la comunidad italiana de 
Red Hook. Alfieri entrevé que la insistencia de Edi en cuanto a las pretensiones de Rodolfo con Kati tiene un origen más profundo y oculto. Por ello le advierte:

Sabés... algunas veces Dios confunde a la gente. Todos amamos a alguien, a la esposa, a los hijos... cada hombre tiene alguien a quien ama, ¿cierto? Pero a veces es demasiado, ¿sabés? Es demasiado amor y se va hacia donde no debe. Un hombre trabaja duro, cría a un bebé, a veces es una sobrina ... y nunca se da cuenta pero con los años ... hay demasiado amor por la sobrina. ¿Me entendés lo que te estoy diciendo? (Miller, 2016, p. 39)

Edi, perplejo, pregunta: “¿qué quiere decir, que no debo cuidarla?” (Miller, 2016, p. 39). En el montaje, la interpretación del actor Antonio Rojas sugiere que Edi se encuentra confundido en cuanto a sus propias pasiones y quizá quiere convencerse a sí mismo que lo que está haciendo es cuidar a Kati, velar por su bienestar, guardarla de un peligro, es decir, cumplir con el deber moral de un buen padre o guardián. Alfieri ha captado que el amor de Edi hacia Kati ha tomado un curso que no debe tomar y le aconseja que lo detenga: "vos ya hiciste tu trabajo, a partir de hoy ella hace su vida: deseale suerte y dejala ir ... Porque no hay leyes para esto, Edi, decidite, a la ley no le interesan estas cosas" (Miller, 2016, p. 39).

Pero Edi no se conforma y no logra detener sus pasiones. Él considera que cumplió con su deber de cuidar a la niña como su tío y guardián, pero el desenlace ha sido injusto. Él trabajó duro y se sacrificó por Kati pero todo ha terminado en un robo: "iy ahora tengo que sentarme en mi propia casa y ver a un hijo-de-puta maleante como ese... que vino de cualquier lado! ¡Le di mi propia casa para dormir! ¡Le di mis propias sábanas para cobijarse; y él viene y se la lleva y pone sus mugrosas y asquerosas manos sobre ella como un maldito ladrón!" (Miller, 2016, p. 40). Edi siente que hay una injusticia en esto pero es incapaz de ver que Rodolfo no ha transgredido la justicia sino sus propios códigos morales. Por un lado, Rodolfo debería ser un trabajador esmerado pero escondido en las sombras y conformado con tener techo y comida. Por otro, Kati debería quedarse en casa protegida por él y, si se marcha, debería ser para estar con "otro tipo de gente", en una "oficina de abogados" de Manhattan por ejemplo, jamás trabajando con plomeros en Brooklyn y casada con un inmigrante siciliano, afeminado y homosexual según las normas de masculinidad de su barrio portuario (Miller, 2016, p. 11).

Alfieri, intentando ayudarle y torcer su destino, le insiste a Edi. Es natural que Kati quiera hacer su vida con un hombre, pues ya es una mujer: "quiere casarse, Edi. No puede casarse contigo o ¿si puede?” (Miller, 2016, p. 40). Edi, al escuchar explícitamente un deseo que él mismo quiere ocultarse, responde consternado y furioso: “i¿qué está diciendo?! ¡¿Casarse conmigo?! ¡No sé de qué carajos está hablando!” (Miller, 2016, p. 40). Alfieri entonces comprende que no habrá manera de detener las pasiones de Edi, tan poderosas como el fatum. El estibador va encaminado a la tragedia. Según la sabiduría de una anciana del barrio de quien Alfieri busca 
consejo, solo queda rezar por Edi, es decir, rogar por una intervención divina donde el consejo humano y la buena voluntad no pueden auxiliar (Miller, 2016, p. 41).

Los eventos siguen su curso inexorable debido a la incapacidad de Edi de dominar sus propios sentimientos. Intenta impedir la relación entre Rodolfo y Kati de formas cada vez más agresivas y amenazantes. Esto deteriora su relación con Beatriz, quien percibe, como Alfieri, las pasiones ocultas de su esposo, y con Marco, quien busca proteger a su hermano menor pero se ve limitado por su vulnerabilidad como inmigrante ilegal. Hasta que un día Edi llega a casa, descubre a Kati y Rodolfo solos en el dormitorio y pierde total control sobre sus pasiones. Se desmadeja. Ordena a Rodolfo marcharse y cuando Kati le dice que debe irse ella también, se lo prohíbe e intenta someterla, no solo con su autoridad, sino con violencia física: la abraza y la besa. Rodolfo se le enfrenta y Edi lo somete y también lo besa. En el entrevero entre los tres personajes hay violencia, desprecio, desafío, horror, incredulidad, rabia, impotencia y dolor. Antes de marcharse, Edi los amenza a ambos: "no me provoqués, Catarina. Tené cuidado, submarino. Por ley tendrán que botarte de regreso al agua. Pero me das pena. Largate y no le volvás a poner una mano encima a menos que querás salir de aquí con los pies por delante" (Miller, 2016, p. 54). Entregado a las normas de un patriarcado opresor y falto de cualquier dominio propio, Edi intenta imponer su poder sobre su niña y amenaza a su competidor.

Pero no logrará detener el curso natural de las cosas. Cuando Edi consulta de nuevo con Alfieri si no hay manera de impedir el matrimonio, el abogado le dice: "moralmente y legalmente hablando no tenés derechos, no podés detenerlos; ella es un sujeto libre" (Miller, 2016, p. 55). Al hablar de moral, Alfieri no se refiere a las normas sociales del patriarcado, sino al sentido de justicia que hemos denominado ético. En cuanto a la ley, le advierte: "la ley es la naturaleza. La Ley es sólo una palabra para lo que tiene derecho a suceder. Cuando la ley se equivoca es porque hay algo que no es natural, pero en este caso es natural y un río te va a ahogar si ahora tratás de atravesarlo. Déjala ir y bendecila" (Miller, 2016, p. 55). Es decir, la ley positiva es justa cuando se ajusta a la ley natural, es decir, a la que está escrita en el orden natural de las cosas. Ley natural es sinónimo de justicia. El matrimonio de Kati con Rodolfo es expresión natural de su amor y la ley es justa al permitirlo. Aunque Edi considere que en esa unión hay injusticia, es él quien se equivoca al aplicar códigos sociales, especialmente patriarcales, errados. La muchacha no le pertenece, ni necesita más su protección de guardián, ni siente atracción erótica por él. Su amor es agradecimiento y cuidado de hija. Sin embargo las pasiones de Edi siguen su cauce fuera de todo control. Alfieri anticipa, con sagacidad, las acciones de Edi cuando este gira para marcharse. Compadecido y alarmado le ruega: "¡no tendrás un solo amigo en el mundo Edi! Aún los que te entiendan estarán en tu contra, incluso aquellos que sientan lo mismo que vos te van a despreciar" (Miller, 2016, p. 55). El abogado italiano entiende los códigos sociales que desprecian y condenan al ostracismo al traidor, al soplón, al que colabora con la represión 
policial en contra de los miembros de la comunidad italiana en Brooklyn. Pero Edi denuncia anónimamente ante las autoridades de inmigración la presencia de Marco y Rodolfo en su propio apartamento. Irónicamente, como él mismo le había advertido a Kati antes de la llegada de los primos de Bea, "es más fácil recuperar un millón de dólares robados que recuperar las palabras que dijiste para delatar a alguien” (Miller, 2016, p. 15).

Las consecuencias se salen del control de Edi. Otros submarinos, familiares de Lipari el carnicero, son capturados junto con Marco y Rodolfo para ser deportados y la comunidad está segura, aún sin poder probarlo, que Edi ha sido el delator. En el montaje, Marco y Lipari le escupen en la cara. Todos lo marginan. Por un lado, Edi ha cometido una injusticia, aunque esta se apegue a la letra de la ley al denunciar a dos inmigrantes ilegales. Pero más allá de violentar el sentido de justicia y la desobediencia civil de la comunidad, ha transgredido normas sociales, pues ha colaborado con los represores y traicionado a amigos y vecinos que comparten su origen y su sangre. Marco le denuncia públicamente al gritarle frente a los vecinos tras ser arrestado: “¡ese! ¡Ese mató a mis hijos! ¡Ese se robó la comida de mis hijos!” (Miller, 2016, p. 64). Ha sido injusto. Edi intentará recuperar su buen nombre y su honor, pero no lo logrará. A Lipari le dice: "ien nombre de Cristo, yo los protegí, les di mis propias cobijas" (Miller, 2016, p. 64). Edi es incapaz de mirarse a sí mismo, de asumir la responsabilidad de sus acciones. Intenta convencer a los demás, porque se ha convencido a sí mismo, de que él fue traicionado, perjudicado por unos malagradecidos. Exige disculpas públicas de Marco para recuperar su buen nombre.

Según Lynn Nottage, un tema prominente que atraviesa toda la obra de Miller es la tensión entre personajes que son víctimas de sus propias falencias morales y personajes que son víctimas de sus convicciones morales (2016, p. xiv). En el caso de Panorama, Marco pertenece a la segunda categoría, pero Edi acarrea la tensión entre ambas categorías dentro de sí mismo: es víctima tanto de sus falencias con respecto al bien superior de la justicia como de sus costumbres morales: denuncia injustamente y se aferra al supremo valor comunitario de su buen nombre. En medio de estas tensiones, cuando Edi y Marco se enfrentan en el desenlace de la trama, Bea es el personaje más sagaz y sensato. Justo después de una confrontación entre Edi y Kati en la cual Bea intenta mediar, Rodolfo se presenta para advertirle a Edi que Marco se apresta a vengar su honra y la injusticia cometida. Bea le ruega a su esposo: "vámonos a otra parte. Vení. Vos y yo. No quiero que estés aquí cuando él venga. Voy por tu abrigo" (Miller, 2016, p. 68). Pero Edi se niega a dejar su casa, la cual es su territorio patriarcal. Edi no ceja ni recapacita pues es Marco quien tiene su buen nombre y, aferrado a los códigos morales del honor público, quiere que Marco se retracte de sus acusaciones. Previendo el desenlace violento, Bea le pregunta: “isólo la sangre es buena?” (p. 69). Agrega: “y qué es lo que sí importa? ... ¿Quién puede regresarte tu nombre? Oíme, te amo, te estoy hablando, te amo; si Marco te besa la mano allá afuera, si se arrodilla, ¿qué más te puede dar? Eso no es lo que querés" (p. 69). Bea por fin revela 
lo que ha percibido desde el inicio, lo que ni siquiera Edi es capaz de admitir ni admitirse a sí mismo, a saber, que lo que más interesa a Edi no es su honor, su buen nombre público de acuerdo con las normas sociales. “¿Querés algo más, Edi, y nunca podrás tenerla a ella!” (p. 69). Bea entiende que las pasiones de Edi yacen más profundo que su sentido de justicia, su respeto por la ley y su apego a los códigos sociales de moralidad. Edi y Kati reaccionan consternados, pero Bea concluye: "ila verdad no es tan mala como la sangre, Edi! Creeme, decile adiós a Kati para siempre!” (p. 69). Pero ni siquiera la verdad dicha por Bea detiene el derramamiento de sangre.

Marco es un hombre atrapado entre los requerimientos de su sentido de justicia y de la honorabilidad social y las necesidades de su familia en Sicilia. Alfieri y Kati visitan a los hermanos en la cárcel cuando ya han sido arrestados. Alfieri le ofrece a Marco sacarlo bajo fianza con la condición de que prometa no vengarse de Edi. Kati y Rodolfo intentan persuadirlo de prometer para que Marco pueda asistir a su boda. Kati argumenta que ya ha escupido en la cara a Edi y, además, aduce razones familiares y prácticas: "usted tiene esposa e hijos, Marco. Puede seguir trabajando hasta que sea la audiencia, en lugar de estar aquí encerrado" (p. 65). Pero Marco considera esa promesa una deshonra. Alfieri le aclara: "prometer no matar no es una deshonra" (p. 66). Marco, extrañado, pregunta que se hace en EE.UU. con un hombre como Edi, y Alfieri responde: "nada. Si obedece la ley, él vive. Eso es todo" (p. 66). La réplica de Marco es inmediata y tajante: “'la ley? Toda la ley no está en un libro" (p. 66). Esta sentencia es central, tanto en el texto de Miller como en el montaje, pues se cita en el programa impreso y en las proyecciones de vídeo que forman parte de la puesta en escena. ¿Qué quiere decir?

Según la presente lectura, la sentencia tiene un doble significado. Por un lado, hay normas morales comunitarias que para Marco tienen el estatus de leyes no escritas. Sobre Edi ya ha dicho: "en mi país él ya estaría muerto. No viviría tanto" (p. 65). Los mismos miembros de la comunidad deben hacer valer y respetar esas normas. Por otro lado, la ley en cuanto expresión de la justicia, no se reduce a la ley positiva, legislada y escrita. Edi ha sido injusto aunque no haya violentado ninguna ley escrita. "Degradó a mi hermano. Mi sangre. Le robó a mis hijos, se burló de mi trabajo. ¡Yo trabajé para venir aquí, señor!”, exclama Marco y añade: “¿no hay ley para eso? ¿Dónde está la ley para eso?” (p. 65). Alfieri, quien ya ha dicho que toda la ley sí está en un libro y no hay otra ley positiva, ahora responde, quizá con un tono de admisión: "no hay ninguna" (p. 65). Marco confiesa: "No entiendo este país" (p. 65).

Esto es revelador de la experiencia del inmigrante con respecto a las normas morales preponderantes en la sociedad a la que ha llegado. Según la filósofa argentina María Lugones, una persona puede tener varias formas de aceptar o resistir las normas vigentes en el mundo social en que se encuentra. La persona puede conocer todas las normas y, además, estar de acuerdo con ellas. O puede conocerlas y obedecerlas, aunque esté en desacuerdo con algunas. 
Puede conocerlas pero resistirlas, al menos aquellas con las que discuerda. Puede desconocerlas y hasta infringirlas sin proponérselo. Las personas que pertenecen a grupos sociales dominantes tienen más motivos para adoptar la primera postura. Las que pertenecen a grupos sociales subalternos y oprimidos puede adoptar variantes de las otras posturas y desarrollar diversas estrategias de resistencia y desobediencia (2003). En el caso de Marco, las costumbres morales y leyes vigentes en el Brooklyn estadounidense le dejan perplejo. Se encuentra ante una encrucijada: obedecer las nuevas costumbres morales y leyes escritas, aunque le parezcan deshonrosas o desobedecerlas en favor de sus propias costumbres morales sicilianas y pagar las consecuencias sociales y legales impuestas por las nuevas normas. A pesar de su perplejidad y, visiblemente, avergonzado, Marco finalmente promete no vengarse. Alfieri paga su fianza. Quizá previendo que Marco sentirá aún el doble peso de su sentido de la justicia y de la honorabilidad, Alfieri le toma una de sus manos (en el montaje, cierra y muestra su puño derecho) y exclama: "esto no es Dios, Marco. ¿Me oye? Solo Dios hace justicia" (Miller, 2016, p. 65).

Sin embargo, Marco no soportará finalmente ese doble peso. Se enfrentará a Edi en la escena final y le matará en defensa propia con el cuchillo que este ha sacado. La confrontación se plantea, finalmente, en términos de las normas morales comunitarias. Edi le reclama directamente: "irestregar el vecindario con mi nombre, como si fuera un trapo sucio! Quiero mi nombre, Marco. Ahora, dame mi nombre y vamos juntos a la boda" (Miller, 2016, p. 70). Y a Bea y Kati les dice: "Marco sabe la diferencia entre el bien y el mal. Décile a la gente Marco, ¡déciles que sos un mentiroso! Vamos, mentiroso, ¡vos sabés lo que hiciste!” (Miller, 2016, p. 70). Edi podría ser un farsante en busca de enturbiar públicamente la verdad que él bien conoce. Pero según esta lectura, influenciada por la actuación de Rojas, es más razonable interpretar que las normas morales comunitarias y su sentido de dignidad pesan tanto sobre su propia psique que es incapaz de reconocer ante los demás y reconocerse a sí mismo que las ha violentado. Marco simplemente le grita “ ‘animal!” (Miller, 2016, p. 70), pues un hombre que ha quebrantado esas normas no merece más ser llamado por su nombre.

Cuando Edi yace herido de muerte, son Beatriz y Catarina quienes le llaman repetidamente por su nombre, una y otra vez. Eran ellas, las mujeres que lo amaban, quienes realmente podían honrar su nombre y devolvérselo. Pero Edi, preso él mismo por las normas de masculinidad y honorabilidad de la sociedad patriarcal que lo crió, no pudo entenderlo a tiempo. No pudo disfrutar del amor y la gracia que Beatriz le ofrecía para redimirlo en la intimidad. Quizá lo lamenta al exhalar: “iMi Bea!” (Miller, 2016, p. 70). En su discurso final, Alfieri ofrece sus propias conclusiones. Dirigiéndose directamente a la audiencia desde su distante despacho convertido en púlpito, nos dice: 
Ahora, en la mayor parte de los casos, conciliamos con arreglos parciales y a mí me parece que así es mejor. Pero la verdad hace justicia, porque a pesar de saberse lo equivocado que él estaba, y que su muerte fue inútil, tiemblo, porque debo confesarles que algo perversamente puro me atrae de su recuerdo... algo no puramente bueno, si no que él mismo era esencialmente bueno, porque se dejó conocer totalmente y por eso creo que lo voy a querer más que a cualquiera de mis clientes más sensatos. Y aún así, es mejor aceptar un acuerdo parcial, ¡así debe ser! Así pues, lo lloro -lo admito- con cierta...alarma (Miller, 2016, pp. 71-72).

Según la presente lectura, para Alfieri los arreglos, las conciliaciones, los acuerdos ante los conflictos, a menudo por medio de la legislación escrita, en general, son mejores. Son más útiles al evitar sufrimiento y violencia. Ya ha dicho antes que la ley, romana o estadounidense, es civilizadora; civiliza, por ejemplo, a los sicilianos y sus descendientes. Y sin embargo, por esos acuerdos parciales y legales a menudo renunciamos a nuestro sentido de la justicia y a nuestras normas de moralidad. Y a menudo también nos ocultamos, nos reprimimos, fingimos. Edi se vio atrapado en ese conflicto y aunque erró, se develó completamente como sujeto de ese conflicto pasional entre justicia, ley y moralidad. Las pasiones le dominaron y le destruyeron, dañaron a sus personas más queridas y perjudicaron a hombres y familias inocentes en una comunidad de inmigrantes. Sin embargo, Alfieri se estremece, pues aunque debería quizá condenar éticamente a Edi, no puede hacerlo. Su debacle pasional, ética y moral es una posibilidad más, un riesgo palpable y siempre presente, de la condición humana.

\section{Dinámicas de la tragedia}

A manera de conclusión, en vez de recapitular los puntos ya argumentados, consideremos una pregunta con respecto a las dinámicas que llevan a la tragedia final en Panorama desde el puente. En un intenso momento de conflicto después de la delación, Kati ha llamado a Edi "rata" (Miller, 2016, p. 68). Este está a punto de agredirla -en la puesta en escena, Edi voltea la mesa y la revienta contra el piso violentamente. Bea intenta calmarlo y a Kati le dice: "entonces todos deberíamos estar en la basura. Vos y yo también. No digás eso. Todo lo que ha sucedido lo hicimos todos, y eso, que no se te olvide nunca Catarina" (Miller, 2016, p. 68). Estas líneas son de difícil interpretación. El propio Miller escribió que para él mismo era un misterio cómo los intereses y fines de cada personaje y las interacciones entre todos se combinaron para llevar a Edi hacia su destino (Steinberg, 1960, p. 337) · ¿Cuáles son las dinámicas que llevan a la tragedia de Edi Carbone? Aunque sea un misterio, el texto de Miller y las interpretaciones actorales en la puesta en escena dan pistas de algunas de esas dinámicas. A partir del análisis realizado, podemos señalar dos de ellas.

9 Steinberg cita el mismo artículo de Miller en el New York Times el 25 de setiembre de 1955. 
Primero, la tragedia resulta de múltiples conflictos en la red de fines personales, relaciones y afectos que se establecen entre los personajes. Si consideramos a los dos personajes inmigrantes, Marco y Rodolfo, recordamos que el primero persigue fines, establece relaciones con lugares, personas y comunidades y expresa afectos acordes con las expectativas sociales para un inmigrante. El segundo, sin embargo, transgrede cada una de esas expectativas. Esto desata el rechazo de Edi hacia Rodolfo y la consecuente confrontación con Marco, a pesar de las intermediaciones afectivas de Bea en favor de sus primos. Además, las pasiones ocultas de Edi, principalmente, su atracción erótica por su sobrina política lo llevan a violentar relaciones de confianza con todos sus familiares. Rechaza sexualmente a Bea y le miente, intenta besar a Rodolfo para humillarlo (la interpretación actoral no sugiere un impulso homoerótico, lo que variaría el análisis, sino una agresión para dominar), besa a Kati sin su consentimiento y por la fuerza y delata a los primos de Bea. El análisis de esta red de fines, relaciones y afectos podría ampliarse, pero el marco teórico queda suficientemente esbozado para señalar cómo contribuye a la tragedia.

Segundo, la tragedia deviene de la forma en que los personajes lidian con el conflicto entre ley, justicia y costumbres morales. En el contexto de Panorama, por ley los inmigrantes ilegales deben ser denunciados para que sean deportados de EE.UU. Por justicia, es mejor proteger y apoyar a seres humanos que buscan sobrevivir y sustentar a sus familias, a pesar de que transgreden las leyes migratorias de un estado, que colaborar para que tales leyes migratorias se cumplan. Por costumbre moral, los descendientes de italianos residentes en Brooklyn protegen a los nuevos inmigrantes italianos del acecho de la policía y la ley. Por costumbre moral, sin embargo, los inmigrantes ilegales deben trabajar y callarse sin perjudicar los intereses de los ciudadanos descendientes de inmigrantes. Por costumbre moral también, quienes colaboran con la policía y denuncian inmigrantes ilegales son considerados soplones y traidores y la dignidad, la honorabilidad de su nombre, se ve mancillada. Por costumbre moral, cuando el buen nombre y la dignidad son violentadas requieren venganza en nombre de la integridad. Las formas en que los distintos personajes, sujetos cada uno a sus propias pasiones, lidian con las tensiones entre todas estas normas conducen inexorablemente a la tragedia de Edi Carbone y su familia. Vista desde esta perspectiva, la tragedia en Panorama refleja situaciones trágicas de la vida contemporánea de inmigrantes indocumentados, sus familias, vecinos y allegados. La situación de ilegalidad los hace vulnerables y a menudo dependientes del sentido de justicia y las costumbres morales de quienes les rodean. Por otra parte, algunas personas que se relacionan con ellos pueden explotarlos o perjudicarlos, aprovechándose de su vulnerabilidad legal, desoyendo o apagando el sentido de justicia. En parte por esto, el texto y montaje de Panorama representan un llamado relevante y urgente a la reflexión ética en cuanto a nuestra participación directa o indirecta en la tragedia cotidiana de migrantes e inmigrantes en el mundo actual. 


\section{Referencias}

Anbinder, T. (2002). From Famine to Five Points: Lord Lansdowne's Irish Tenants Encounter North America's Most Notorious Slum. American Historical Review, 107(2), 351-387.

Campos, D. G. (2011). Understanding immigration as lived personal experience. En G. Pappas (Ed.), Pragmatism in the Americas (pp. 245-261). New York: Fordham University Press.

Campos, D. G. (2017). Loving Immigrants in America: An Experiential Philosophy of Personal Interaction. Lanham, Maryland: Lexington Books.

Hesse-Biber, S. (1979). The ethnic ghetto as private welfare: A case study of southern Italian immigration to the United States, 1880-1914. Urban E Social Change Review, 12(2), 9-15.

Lugones, M. (2003). Playfulness, 'World'-traveling, and loving perception. Pilgrimages/Peregrinajes: Theorizing coalition against multiple oppressions. Lanham, Maryland: Rowman \& Littlefield.

McKeown, A. (2003). Ritualization of Regulation: The Enforcement of Chinese Exclusion in the United States and China. American Historical Review, 108(2), 377-403.

Miller, A. (2015). A view from the bridge. The Penguin Arthur Miller: Collected plays. New York: Penguin.

Miller, A. (2016). Panorama desde el puente: Guión de puesta. (Trad. y notas T. De la Ossa). San José, Costa Rica: Inédito.

Nottage, L. (2015). Foreword. The Penguin Arthur Miller: Collected plays (pp. xiii-xvii). New York: Penguin.

Peirce, C. S. (1992). The law of mind. The Essential Peirce: Selected Philosophical Writings, (Vol. 1, Eds. N. Houser \& C. Kloesel). Bloomington: Indiana University Press.

Riis, J. (2010). How the other half lives (with related documents). (Ed. D. Leviatin, 2nd ed.). Boston: Bedford / St. Martin's.

Sófocles. (2009). Antígona (E. I. Granero Trans, Tercera ed.). Buenos Aires: Eudeba.

Steinberg, M. W. (1960). Arthur Miller and the idea of modern tragedy. The Dalhousie Review, 40, 329-341.

Thoreau, H. D. (1992). Resistance to Civil Government. Walden and Resistance to Civil Government (Ed. W. Rossi, Second ed.). New York: W.W. Norton \& Co.

Trout, L. (2010). The Politics of Survival: Peirce, Affectivity, and Social Criticism. New York: Fordham University Press. 